\title{
Warfarin and cataract extraction
}

\author{
G A ROBINSON AND A NYLANDER \\ From University Hospital of Wales, Cardiff
}

SUMMARY Ten cataract extractions were performed on eight patients for whom warfarin was not discontinued prior to surgery. Three were complicated by hyphaema. No retrobulbar haemorrhages occurred in the four cases given a local anaesthetic. Cataract surgery can be performed successfully without discontinuing warfarin.

It is usual to discontinue warfarin before elective surgery, but for some patients this is not advisable because it would place them at risk of possibly fatal embolism or thrombosis. We reviewed 10 cataract extractions performed on eight patients for whom anticoagulation was not discontinued in the perioperative period.

\section{Patients and methods}

The 10 cataract extractions were performed between January 1985 and May 1988. There were five men and three women aged 66 to 83 . The reasons for anticoagulation are shown in Table 1 . Three patients were diabetic.

Six operations were performed under general anaesthesia and four under local anaesthesia. Eight were extracapsular cataract extractions, six with posterior chamber intraocular lenses and two in high myopes. Two were endocapsular cataract extractions with posterior chamber intraocular lenses. The British comparative ratio/international normalised ratio (BCR/INR) was measured prior to surgery.

\section{Results}

The range of BCR/INR was 1.5 to 4.5 for all 10 operations and the range for the four under local anaesthetic was 1.5 to $3 \cdot 1$ (Table 2). None of the four cases under local anaesthetic suffered a retrobulbar haemorrhage.

A posterior chamber intraocular lens was inserted in all eight cases requiring it.

Three hyphaemas occurred. The first was a small operative hyphaema and cleared by the third post-

Correspondence to Gillian A Robinson, FRCS Ed, Ophthalmology Department, University Hospital of Wales, Heath Park, Cardiff CF4 4XW. operative day. The INR on the day of surgery was $1 \cdot 5$. The second was a small operative hyphaema which cleared by the first clinic appointment at two weeks. The INR was 4.5 on the day of surgery. In the third case a $3 \mathrm{~mm}$ hyphaema was present two weeks postoperatively. The INR at the time of surgery was $3 \cdot 1$, and no hyphaema was present immediately after operation. The INR was checked in the clinic and was 4.7. This patient died before his third clinic appointment. No hyphaemas followed cataract surgery in the diabetics and none in the three cases where corneal sections were used.

\section{Discussion}

If anticoagulation is not discontinued, it is not known at what level of INR the risk of ocular complications is reduced without putting the patient at risk of

\section{Table 1 Reasons for anticoagulation}

Femoral embolus, aortic valve replacement, coronary artery bypass Mitral valve replacement

Mitral valvotomy, homonomous hemianopia

Arterial thrombosis (leg)

Atrial fibrillation, embolic transient ischaemic attack

Deep vein thrombosis

Mixed aortic and mitral valve disease

Mixed mitral valve disease

Table 2 Range of $B C R / I N R$

\begin{tabular}{ll}
\hline BCR/INR & Number of patients \\
\hline $1 \cdot 5-2 \cdot 4$ & 5 \\
$2 \cdot 5-3 \cdot 4$ & 4 \\
$3 \cdot 5-4 \cdot 4$ & 0 \\
$4 \cdot 5$ & 1
\end{tabular}

$\mathrm{BCR}=$ British comparative ratio. $\mathrm{INR}=$ international normalised 702 
embolism or thrombosis. Four of our patients were not fit for general anaesthetic, and the risk of retrobulbar haemorrhage with local anaesthesia was a very real consideration.

The British Society for Haematology recommended therapeutic ranges for $\mathrm{BCR} / \mathrm{INR}^{1}$ are: $2 \cdot 0$ to 3. 0 for the treatment of deep vein thrombosis (DVT), pulmonary embolism, and transient ischaemic attack (TIA); 3.0 to 4.5 for recurrent DVT and pulmonary embolus (PE), and arterial disease including cardiac prosthetic valves and grafts.

In a survey of 135 members of the American Intraocular Implant Society by Stone et al. ${ }^{2} 75 \%$ withheld warfarin prior to and following surgery. Twenty-two instances of ocular complications including hyphaema, conjunctival/incisional bleeding, retrobulbar haemorrhage, retinal haemorrhage, and expulsive haemorrhage were reported. None of the 10 ophthalmologists who continued anticoagulation listed any adverse effects. Systemic complications attributed to withholding anticoagulation included death from cerebrovascular accident, TIA, revision of coronary bypass graft, cerebral embolism in a patient with an artificial heart valve, PE and DVT. Some ophthalmologists gave platelets, vitamin $\mathrm{K}$, heparin, and fresh frozen plasma preoperatively.

Hall et al. ${ }^{3}$ contend that anticoagulants which are necessary to control a life threatening process should not be terminated before intraocular surgery. In their most recent series of 49 cataract operations ${ }^{4}$ all were performed under local anaesthesia. Most of the patients underwent a peripheral iridectomy. Eighteen of the operations were intracapsular extractions, 11 with medallion intraocular lenses, and 30 were extracapsular extractions with posterior chamber intraocular lenses. Prothrombin times were 1.5 to twice normal in 20 patients, were normal in 11 , and between normal and 1.5 times normal in 18 . Three hyphaemas occurred, and two patients died within six months of surgery.

In our 10 patients three hyphaemas occurred. Two were mild and did not adversely change the final outcome. The third hyphaema appeared some time postoperatively and was associated with a rise in INR from $3 \cdot 1$ to $4 \cdot 7$. It should be remembered that the INR may increase if additional drugs such as prophylactic antibiotics are given, but no additional drugs were given in this particular case.

Spontaneous hyphaema has been described as a result of warfarin therapy. ${ }^{5}$ Maida has reported three anticoagulated patients with iris clip lenses who developed microhyphaemas some months postoperatively. ${ }^{\circ}$

Surgical technique may be modified to reduce the risk of bleeding, for example, a corneal section, avoiding an iridectomy or iris suture, careful cautery, the use of sodium hyaluronate, and an endocapsular technique placing loops into the capsular bag to prevent erosion of the loops into the ciliary sulcus. Local anaesthesia could also be modified, for example without retrobulbar injection, ${ }^{7}$ to reduce the risk of bleeding.

Cataract surgery can be performed successfully without discontinuing warfarin. It would seem reasonable to reduce the warfarin before surgery until the INR is just within the recommended therapeutic range and to keep a careful check of the INR in the postoperative period if additional drugs are given.

We thank Mr P A Graham, Mr P V Mills, Mr J W Hunter, and Mrs L Beck for permission to include their patients in this study.

\section{References}

1 Poller $\mathrm{L}$. Therapeutic ranges in anticoagulant administration. Br Med J 1985; 290: 1683-6.

2 Stone LS, Kline OR, Sklar C. Intraocular lenses and anticoagulation. J Am Intraocul Implant Soc 1985; 11: 165-8.

3 Hall DL, Steen WH, Drummond JW. Anticoagulants and cataract surgery. Ann Ophthalmol 1980; 12: 759-60.

4 Hall DL, Steen WH, Drummond JW, Byrd WA. Anticoagulants and cataract surgery. Ophthalmic Surg 1988; 19: 221-2.

5 Koehler MP, Sholiton DB. Spontaneous hyphema resulting from warfarin. Ann Ophthalmol 1983; 15: 858-9.

6 Maida JW. Intraocular lenses and anticoagulation therapy. J Am Intraocul Implant Soc 1979; 5: 36.

7 Editorial: Why retrobulbar anaesthesia? Br J Ophthalmol 1988; 72: 1 .

Accepted for publication 3 February 1989. 